\title{
Ações afirmativas de gênero na política brasileira: interfaces entre reconhecimento, redistribuição e representação política
}

\author{
Gender affirmative actions in brazilian politics: interfaces between \\ recognition, redistribution and political representation
}

\author{
1 Amanda Oliveira de Sousa oliveiraamanda482@gmail.com \\ 2 Jahyra Helena Pequeno dos Santos
}

1 Mestranda em Direito pela Universidade Federal Rural do Semi-Árido (UFERSA). Especialista em Direito Constitucional pela Universidade Regional do Cariri (URCA). Graduada em Direito pela Universidade Regional do Cariri (URCA). Advogada. Universidade Federal Rural do Semi-Árido (UFERSA).

2 Doutoranda em Direito Constitucional pela Universidade de Fortaleza (UNIFOR). Mestre em Direito Constitucional pela Universidade de Fortaleza (UNIFOR). Especialista em Direitos Humanos Fundamentais pela Universidade Regional do Cariri (URCA). Professora Assistente da Universidade Regional do Cariri (URCA). Universidade Regional do Cariri (URCA).

\section{Resumo}

Nas últimas décadas, a população feminina passou a demandar ativamente pela inserção da perspectiva de gênero no acesso aos cargos políticos, o que levou à adoção de ações afirmativas nos processos eletivos. Sobre elas, este estudo objetiva investigar de que forma as cotas de gênero têm contribuído para a igualdade de gênero na política brasileira. Orienta-se pelo método de abordagem dedutivo e pelos métodos de procedimento histórico e comparativo, utilizando-se da pesquisa bibliográfica. Inicialmente, faz-se uma abordagem acerca das correlações entre as estruturas gênero e poder presentes na sociedade e o acesso à representação política. Em seguida, são trabaIhadas as noções de reconhecimento e redistribuição, para compreender a natureza das ações afirmativas de gênero na política. Percorre-se também o plano histórico de orientação à adoção dessas medidas e se delimita o caso brasileiro, evidenciando que a política de cotas não surtiu o impacto esperado, pois a ocupação feminina no poder, mesmo com acréscimos, continuou pouco expressiva. Indica-se que coexistem óbices institucionais, culturais e socioeconômicos que refletem sobre o sucesso das cotas, reduzindo suas possibilidades de ação. Conclui-se que, embora tenham representado um avanço importante na busca pela igualdade de gênero na política, as cotas não têm o condão de, por si só, promovê-la, pois o aumento da eficácia delas está condicionado a mudanças socioculturais estruturais e estas não podem ser alcançadas isoladamente com remédios reparatórios.

\section{Palavras-chave:}

Representação política. Ações afirmativas. Igualdade de gênero.

\begin{abstract}
In recent decades, the female population has actively demanded the insertion of gender perspective in the access to political positions, which has led to the adoption of affirmative actions in the electoral processes. About them, the study aims to investigate how gender quotas have contributed to gender equality in Brazilian politics. It is guided by the deductive approach method and the historical and comparative procedure methods, using the bibliographical research. Initially, an approach is made about the correlations between gender and power structures present in society and the access to political representation. Then, the notions of recognition and redistribution are developed, in order to understand the nature of gender affirmative actions in politics. The historical plan that guides the adoption of these measures is also explored and the Brazilian case is delimited, showing that the quota policy did not have the expected impact, since women's occupation in power, even with increases, remained little expressive. It is indicated that institutional, cultural and socioeconomic obstacles coexist and reflect on the success of quotas, reducing their possibilities of action. It is concluded that, although they represented an important advance in the search for gender equality in politics, quotas do not have the capacity, by themselves, to promote it, because the increase in their effectiveness is conditioned by structural socio-cultural changes and these cannot be achieved, in isolation, with reparative remedies.
\end{abstract}

\section{Keywords:}

Political representation. Affirmatives actions. Gender equality.

\section{Como você deve citar?}

SOUSA, Amanda Oliveira de; SANTOS, Jahyra Helena Pequeno dos. Ações afirmativas de gênero na política brasileira: interfaces entre reconhecimento, redistribuição e representação política. Cadernos UniFOA, Volta Redonda (RJ), v. 16, n. 46, p. 1-11, ago, 2021. 


\section{INTRODUÇÃO}

$\mathrm{Na}$ concretização das reinvindicações femininas no campo político representativo, pauta-se cada vez mais a exigência da adoção da perspectiva de gênero para democratizar os espaços de poder, por intermédio de mecanismos voltados ao aumento da representação feminina em cargos políticos. Através deles, se sobressai a discussão sobre ações afırmativas na política, no que se foca este estudo. Tratando dos fundamentos, do potencial e das carências da política de cotas eleitorais brasileira, indaga-se: elas vêm, de fato, impactando positivamente na construção de espaços de representação materialmente igualitários?

Desenvolvendo esse questionamento, o estudo objetiva investigar como o modelo de cotas de gênero implementado pelo Brasil impacta na busca pela igualdade de gênero na política. Ainda, como objetivos específicos, visa-se: discutir as estruturas de gênero que levam à baixa ocupação de cargos políticos por mulheres no Brasil; averiguar como noções de reconhecimento e redistribuição implicam na compreensão de modelos de ações afirmativas na arena política; e analisar como tais medidas passaram a ser adotadas no mundo e no Brasil, explorando suas deficiências e pontos de avanço.

A pesquisa se orienta pelo método dedutivo, partindo da análise das assimetrias de gênero ainda persistentes no campo político e dos fundamentos das políticas de reconhecimento e de redistribuição, para situar a adesão a políticas afirmativas de gênero na política e enxergar sua efetividade no caso brasileiro. Faz uso também dos métodos comparativo e histórico, utilizados, respectivamente, para realizar o confronto de teorias e modelos de políticas públicas, explicando suas similaridades e diferenças, e para traçar um retrospecto histórico do desenvolvimento das cotas de gênero. Tais métodos são empregados por via de uma pesquisa de cunho essencialmente bibliográfico, que recupera os principais debates na literatura sobre o tema e os analisa de forma esmiuçada.

Inicialmente, se faz uma breve explanação das razões estruturais por trás do distanciamento histórico das mulheres do campo político, expondo como padrões masculinos sexistas e condições socioculturais afetam a entrada e a permanência das mulheres em espaços de poder, contribuindo para a continuidade de desigualdades que afetam não só no desequilíbrio na tomada de decisões, mas na própria qualidade da democracia.

Em seguida, o estudo explana, em linhas gerais, o binômio reconhecimento e redistribuição, fazendo uso das contribuições de Santos (2003) e Fraser (2006). Como se leva o trabalho para a seara política e, dentro dela, para o recorte de gênero, são também ricas as análises de Young (2006) e Pinto (2017).

De posse desse suporte, se trabalha com o contexto de adoção e o impacto das cotas eleitorais de gênero no Brasil, momento em que se acompanha, analiticamente, as razões que justificaram a adesão a esse tipo de remédio de reconhecimento, se pontuam os resultados da incidência dele sobre as candidaturas femininas e se reflete sobre as causas de sua pouca efetividade no aumento dos índices de representação feminina.

\section{INTERSEÇÕES ENTRE GÊNERO, PODER E REPRESENTAÇÃO POLÍTICA}

O tratamento analítico da categoria gênero permite percorrer as camadas de determinado fenômeno ou contexto o percebendo a partir da construção social das diferenças entre os sexos, mais precisamente, explorando o porquê e o como elas nascem e seus enlaces com a evolução de relações que reafirmam a predominância masculina em certos ambientes. É, assim, uma dimensão essencial para tematizar a dualidade entre homens e mulheres na vida pública. 
Esse dimensionamento do gênero enquanto um conceito necessário para compreender a construção sociocultural em torno das diferenças entre os sexos - que repercute diretamente sobre a categorização da função da mulher na sociedade - se define sem apego a oposições fixas, como "[...] uma forma primeira de significar as relações de poder." (SCOTT, 1990, p. 21).

Entretanto, o desnudamento de suas correlações não se limita a um binarismo histórico, devendo, por outro lado, contemplar análises detidas às peculiaridades que consolidam a sujeição feminina. Justamente fugindo de qualquer binarismo fixo e da visão de uma mulher universal, Crenshaw (2002) problematiza as diferenças que contornam as desigualdades de gênero, tematizando as variadas marcações específicas que, na experiência feminina, trazem formas particulares de se falar em discriminações de gênero. São marcações como as de raça, etnia, classe social e orientação sexual.

A inscrição sociocultural em torno do masculino e do feminino não pode ser vista de maneira uniforme, tampouco autônoma. A análise das relações de gênero, sobretudo nas décadas recentes, percorre o trajeto de transformações na produção de conhecimento e nas configurações sociais, contemplando a sexualidade, as relações de trabalho, a participação feminina na esfera pública e o entendimento de que o gênero não poder ser lido de forma independente, quando confrontado com questões atinentes à raça e à classe (BIROLI, 2018).

Debate-se aqui, inclusive, que, mais do que ver a mulher como um "Outro" invisibilizado, a quem não se permite transitar pelos mesmos espaços que o homem, como posto por Beauvoir (1970), pode-se falar também na mulher negra como um "Outro do Outro", no que sustenta Grada Kilomba ser uma dupla camada específica de opressão que coloca a mulher negra em posição ainda mais silenciada frente ao patriarcalismo (RIBEIRO, 2017).

Não cabe, portanto, enfrentar os obstáculos que se colocam à frente da superação das fronteiras entre o público e o privado para as mulheres sem atravessar o complexo de abordagens que contornam essa oposição. De igual forma, focalizar na seara pública, tratando da dinâmica feminina nesse ambiente, requer análises que se atentem às especificidades que a rodeiam.

Como reflete ainda Biroli (2018), mesmo nas democracias contemporâneas, seus espaços formais de representação assentam-se sobre uma seletividade que lhes é particular e que se associa aos óbices impostos pela divisão sexual do trabalho para desemborcar em obstáculos variados que, por sua vez, impulsionam a exclusão feminina da atuação na cena pública.

No campo político, a conquista do voto feminino, - no Brasil, ocorrida em 1932 e consagrada na Constituição de 1934 - funcionou como um importante instrumento para promover a aproximação da cidadania feminina com a política institucional, entretanto, análises sobre participação política na contemporaneidade devem perpassar pelo entendimento de que tal direito, assim como o de disputar eleições, embora tenham sido incontestáveis avanços, não representaram a igualdade de gênero na política (SANTOS, 2010; BIROLI, 2018).

Isso porque, enquanto a consagração do voto feminino já pode ser vista, em geral, como uma realidade global, não se diz o mesmo da atuação da mulher na condição de representante política, pois ainda permanece, em boa parte, ausente dos espaços formais de representação. Assim como as desigualdades no âmbito doméstico tomaram nova roupagem, mas não deixaram de existir, a ausência que se trata aqui não coincide com a inexistência de mulheres atuando na vida pública, mas se encontra com a inexistência de uma proporcionalidade de fato. 
Comprovando estatisticamente essa realidade, ao tomar-se por recorte a Câmara dos Deputados, Casa Legislativa mais expressiva numericamente, os dados do Tribunal Superior Eleitoral (TSE) das últimas eleições (2018) indicam que apenas 77 mulheres foram eleitas para ocuparem o cargo de Deputada Federal, quantitativo que se confronta com os 436 homens que ocupam a mesma posição (BRASIL, 2019). E, ao se levantar o número de mulheres negras nesse espaço, os números são ainda menos expressivos: dentre as 77 deputadas eleitas, o Brasil registra apenas 10 delas autodeclaradas negras (pretas ou pardas) (BRASIL, 2019).

Foi a prevalência dessa exclusão feminina, e a sua identificação com a discriminação, que fomentou a ampliação do leque de debates sobre o tema. $\mathrm{Na}$ área dos direitos políticos das mulheres, $\mathrm{O}$ que teve como exponente a luta pelo voto continuou nas décadas seguintes, especialmente a partir da década de 1970, e permanece se desdobrando nas discussões atuais acerca das carências da cidadania feminina (PRÁ, 2014).

Diante desse cenário, análises em torno de políticas afirmativas destinadas a incrementar a representatividade feminina nos cargos políticos tomam cada vez mais lugar nos debates que sustentam a necessidade de democratizar em maior escala o poder, a partir do reconhecimento das diferenças de gênero. As entrelinhas dessas discussões passam a ser pormenorizadas.

\section{DO RECONHECIMENTO E DA REDISTRIBUIÇÃO À REPRESENTAÇÃO POLÍTICA}

Os limites à atuação feminina no ambiente de tomada de decisão e a ênfase contemporânea em medidas de cunho reparatório para corrigir e promover mudanças na cena de sub-representação são temas que transitam em um paradigma maior: o da dualidade fincada entre as noções de redistribuição e reconhecimento. Faz-se, importante, portanto, reter as atenções, inicialmente, à análise delas.

Em um primeiro olhar, as lutas por reconhecimento pressupõem a compatibilização da necessidade de reconhecer as diferenças com as reinvindicações pelo combate às desigualdades. A essa consideração chega Santos (2003), ao ponderar que são múltiplas as formas de opressão, levando as diferenciações e subjetividades contidas nelas a ensejarem, analogamente, modos distintos de conceber ideais de justiça, se apontando para uma perspectiva não hegemônica das formas de dominação.

Nessa linha, explica Fraser (2006) que as políticas de reconhecimento se direcionam para a afirmação das especificidades de determinado grupo o diferenciando, e as políticas de redistribuição, normalmente, visam à desconstrução das desigualdades que firmam as aludidas diferenciações.

Observa-se, por esse ângulo, que interligada à compreensão de que a emancipação social se dá através do reconhecimento das diferenças, está, como condicionante de sua efetivação, a necessidade de políticas redistributivas orientadas por concepções alternativas de justiça social que internalizem discursos não opressores e sejam guiadas pelo entendimento dual de que a defesa da igualdade deverá ser uma constante sempre que distinções derem azo à inferioridade, assim como a da diferença deve ser conclamada para evitar a descaracterização imposta pela igualdade (SANTOS, 2003).

Fraser (2006) evoca a adoção de uma perspectiva crítica pelas estratégias de reconhecimento. Para a autora, políticas de reconhecimento das diferenças não podem ser vistas desvencilhadas das de redistribuição socioeconômica, haja vista que igualdade social e reconhecimento são codependentes e precisam ser compreendidos em uma ligação próxima, na qual as restrições socioeconômicas e o desrespeito cultural são preponderantemente simultâneos, se fazendo necessária a integração das duas noções para entender adequadamente as injustiças sociais contemporâneas (FRASER, 2006). 
A redistribuição e o reconhecimento ganham, assim, um caráter ambivalente. São dois lados da justiça social que implicam, necessariamente, no combate às desigualdades socioeconômicas, ao mesmo tempo em que se entende que, mesmo com a redução delas, fatores como o racismo, o machismo e a homofobia continuarão a atingir atores sociais em sua busca pelo reconhecimento, não significando, portanto, a desconstrução de suas identidades como grupo (PINTO, 2017).

Como realça Young (2006), a atuação política dos grupos socialmente minoritários que lutam por reconhecimento dificilmente se atém à pura afırmação identitária, chegando também a instrumentalizar um canal comunicativo para requerer o combate a outras discriminações e desigualdades de cunho social, político ou econômico. Mas, em uma dimensão mais detida às minúcias dessas diferenças, deve-se especificar que as injustiças podem ter fundo socioeconômico ou cultural: as primeiras se circunscrevem às desigualdades provenientes da exploração social e da distribuição de recursos e as segundas decorrem da instituição de certos padrões, como a dominação cultural e a invisibilização (FRASER, 2006).

Em linhas gerais, existem aquelas diferenciações que surgem através de injustiças culturais, por envolverem questões de identidade (por exemplo: desigualdade com as pessoas homossexuais); outras que emanam de injustiças econômicas e sociais (por exemplo: diferenças de classes sociais); e há também uma terceira categoria que congrega as duas primeiras citadas e reúne os recortes de gênero e raça, não se satisfazendo apenas com a redistribuição ou com o reconhecimento (PINTO, 2017).

Em meio a essa explanação, destaca-se que a redistribuição e o reconhecimento até aqui invocados podem se apresentar através de políticas estatais de dois tipos: as afirmativas e as transformativas. As ações afirmativas buscam a reparação dos efeitos da desigualdade sem a intenção de promover modificações na estrutura que as sedimenta; as transformativas visam corrigir esses mesmos efeitos através de alterações na referida estrutura (FRASER, 2006).

De logo, Fraser (2006), embora realce sua importância, indica a incerteza dos efeitos das políticas afirmativas, principalmente quanto ao reconhecimento, como também indaga acerca da suficiência de um e de outro modelo para isoladamente corrigir as desigualdades socioeconômicas e culturais, ao refletir sobre qual seria a combinação ideal, considerando as especificidades das injustiças a que se submete cada grupo.

Dentro do recorte político representativo, toda essa problemática levanta discussões ainda mais particulares, principalmente no que cerne às demandas por representação diferenciada de determinados grupos sociais. A concessão de instrumentos para promover a chegada ao poder de grupos sub-representados é um ponto que permeia algumas controvérsias. Na leitura de Young (2006), pode-se identificar uma cisão entre aqueles que defendem que políticas diferenciadoras do acesso a cargos representativos para alguns grupos promovem ainda mais divisões e os que, assim como a autora, sustentam que essa diferenciação origina processos comunicativos mais democráticos e justos.

Os que se opõem à adoção de instrumentos de diferenciação alegam, sobretudo, que, mesmo dentro de determinados grupos, os componentes dele guardam inúmeras diferenças entre si e, assim sendo, uma representação de grupos intentaria unificar essas identidades, o que poderia reproduzir mais exclusões. A outro giro, na defesa dessas políticas, se argumenta, justamente, a democraticidade que se sobressai das singulares vivências de cada um dos sujeitos integrantes de um grupo de gênero, raça ou etnia (YOUNG, 2006).

Em síntese, os fatores culturais se interligam aos socioeconômicos, acentuando ainda mais desigualdades, de modo que políticas redistributivas que não levem em conta esse aspecto em sua formulação acabarão por reproduzir desigualdades, tendo em vista a relação de dependência entre a 
igualdade política e as condições de vida dos cidadãos, sendo fundamental, por conseguinte, que elas debatam os efeitos da exclusão social (PINTO, 2017).

Dentro desse panorama, se enquadra a questão de gênero no âmbito político. 0 gênero, como se vê, tem caráter duplo quanto às opressões que nele se fundam, podendo ser analisado sob as vertentes da redistribuição e do reconhecimento. Veja-se que, na mesma proporção em que o gênero é um princípio fundante de diferenciações político-econômicas - posto que nutre toda uma cadeia de divisão sexual do trabalho marcada por injustiças distributivas que só podem ser reparadas por ações redistributivas -, é também um problema cultural que simboliza padrões internalizados de machismos e sexismos, os quais, por sua vez, só podem ser modificados pela luta pelo reconhecimento (FRASER, 2006). Visualiza-se o gênero, então, como um fenômeno multifacetado que transposto para a arena política suscita a associação de diversos aspectos para contornar as diferenciações que suas hierarquias edificam.

\section{AÇõES AFIRMATIVAS DE GÊNERO NA REPRESENTAÇÃO ELETIVA: O CASO BRASILEIRO}

A percepção até aqui traduzida é a de que as mulheres são impactadas por dois tipos de injustiças: as socioeconômicas e as culturais. 0 quadro exige, simultaneamente, a incidência de dois tipos de políticas, as redistributivas e as de reconhecimento. No campo da representação política, as cotas de gênero são exemplos de políticas, do tipo afirmativas, que buscam afetar positivamente a igualdade de gênero.

Nas últimas décadas, reinvindicações femininas no campo político passaram a traduzir a exigência de uma perspectiva de gênero para democratizar os espaços de poder, por meio de medidas voltadas ao aumento da representação. A adoção dessas medidas foi resultado do alcance internacional do ativismo de grupos de mulheres e de organizações feministas, notadamente a partir da década de 70 , momento em que efervesceram as discussões sobre as carências que rodeavam a presença feminina na participação e condução dos assuntos públicos (PRÁ, 2014).

Por meio do Direito Internacional dos Direitos Humanos, essa abertura teve como impulso o texto da Convenção sobre a Eliminação de todas as Formas de Discriminação contra a Mulher (CEDAW), que prevê, em seu art. $7^{\circ}$, que os Estados signatários devem tomar medidas para eliminar a discriminação contra a mulher na vida política e, em seu art. $4^{\circ}$, que devem adotar ações afirmativas para a promoção dos direitos das mulheres (BRASIL, 2002).

Ao encontro da CEDAW, citam-se as diretrizes traçadas a partir da Conferência de Beijing ${ }^{3}$, de 1995, que contemplou, em sua Declaração e Plataforma de Ação, a desigualdade de gênero no exercício do poder como uma das áreas críticas de preocupação a ensejarem ações concretas dos Governos, por se considerar, dentre outros motivos, que estereótipos negativos e as limitações de acesso ao trajeto de condução ao poder persistem como graves percalços à representação feminina (PEQUIM, 1995). A Plataforma de Ação de Beijing situou a incorporação de ações afırmativas pelos Estados em uma proporção mínima de $30 \%$ de ocupação parlamentar, meta que era vista como essencial para, ao menos, colocar as mulheres em quantitativo crítico capaz de influenciar na tomada de decisões (PRÁ, 2014).

O ponto em comum dos documentos tratados, como se vê, é o reconhecimento de que a igualdade de gênero na política demanda mais do que fórmulas genéricas, reclamando medidas especiais para auxiliar na sua materialização. De efeito, guiando-se por eles, diversos Estados vêm agregando a

3 Refere-se à IV Conferência Mundial sobre a Mulher, realizada em Pequim, em setembro de 1995. 
seus processos eleitorais uma perspectiva de gênero, através, sobremaneira, de políticas de cotas para mulheres nas candidaturas a cargos políticos, como é o caso do Brasil.

A discussão sobre igualdade de gênero na política não tem se cingido, no entanto, à implementação de cotas eleitorais. 0 tema já se encontra em evolução para o enfoque na paridade política. Com a influência dos debates provenientes do texto Declaração de Atenas (1992) e do Consenso de Quito (2007), passou-se também a se falar em campos representativos efetivamente equilibrados, não apenas contando com uma proporção feminina mínima, mas igualitários em sua ocupação por homens e mulheres (PRÁ, 2014).

Não obstante coincidirem com as cotas quanto ao objetivo maior de democratizar o elemento gênero na representação política, as normas que instituem políticas de paridade não são simples ações afirmativas, vez que, como elucida Martelotte (2016), a paridade não é um mecanismo temporário, mais do que isso, se trata de uma noção com potencial para sedimentar a base da democracia de uma nação. A paridade seria, por esse prisma, uma política de gênero transformativa.

Se as políticas de cotas, como ocorre no Brasil, reservam uma quantidade mínima de vagas a serem preenchidas nas listas de candidatura, as normas de paridade - adotadas por países como, Bolívia, Venezuela e Costa Rica - ultrapassam essa obrigação mínima e preveem que os partidos políticos preencham suas listas de forma igualitária ( $50 \%$ de candidaturas para cada sexo) (ARCHENTI; ALBAINE, 2018).

No entanto, a existência de normas de paridade orientando processos eleitorais ainda não é uma realidade majoritária. Por outro lado, levando-se em conta que, no Brasil, as ações adotadas se enquadram, até o momento, como do tipo afirmativas (leis de cotas) e tendo em vista o aporte teórico que fora levantado sobre elas até então, cabe ater-se ao quadro nacional, trabalhando o impacto das cotas na busca pela igualdade de gênero na política.

Recuperando-se brevemente a origem da política de cotas no Brasil, seu implemento se deu por influência das recomendações de Pequim. A partir delas, em 1995, foi aprovada a Lei número 9.100, que, ao estabelecer as normas para as eleições municipais seguintes, previa a cota mínima de $20 \%$ para as candidaturas de mulheres; em 1997, a Lei n. 9.504 estendeu, em seu art. 10, a medida para os demais cargos eleitos pelo sistema proporcional ${ }^{4}$, se referindo agora não mais a uma cota mínima para mulheres, mas a um percentual mínimo de $30 \%$ e máximo de $70 \%$ de candidaturas de cada sexo (SABINO; LIMA, 2015).

Em 2009, a Lei n. 12.304/09 veio para interpretar o preenchimento das mencionadas vagas como obrigatório, substituindo a expressão "deverá reservar" por "preencherá", além de passar a garantir a reserva de, no mínimo, 5\% do Fundo Partidário para o incentivo da participação feminina na política e de $10 \%$ do tempo de propaganda partidária para difundi-la (BRASIL, 2009).

Não obstante, a despeito dos aprimoramentos realizados sobre a política de cotas legislativas, não houve repercussões tão positivas na proporção de mulheres a se candidatarem. Mesmo com as alterações efetuadas pela Lei número 12.304/09, nas eleições realizadas em 2018, quase dez anos após a nova redação que o diploma legislativo conferiu ao art. 10 da Lei número 9504/97, o percentual de candidaturas femininas só alcançou a marca de $30,06 \%$ de mulheres concorrendo às vagas da Câmara dos Deputados e essa marca não se converteu no número de eleitas, que pontuou apenas 77 Deputadas (BRASIL, 2019).

4 Pela redação legal, excluem-se do sistema de cotas as candidaturas aos cargos do Poder Executivo e do Senado Federal. 
O número de mulheres candidatas aumentou timidamente, percebendo-se que a garantia de um valor numérico mínimo nas listas de candidatura não foi ao encontro do objetivo de aumentar de modo expressivo a representação feminina no poder político. Essa situação pode ser explicada à luz da análise de alguns fatores.

Primeiro, a política de cotas apresenta como deficiência a ausência de punição para o descumprimento do preenchimento mínimo obrigatório das vagas, o que abre brechas para que ele ocorra e, assim, embora a reserva mínima contribua para o aumento das mulheres nos espaços de poder, é preciso que haja uma maior articulação em prol do efetivo cumprimento da legislação (SANTOS, 2015).

A insuficiência também é expressiva porque os obstáculos à efetividade dessas leis são diversos, incluindo: o patriarcalismo persistente no espaço político (com suas devidas interações com aspectos como raça, classe e orientação sexual); o tipo de lista adotado pelo sistema eleitoral; a interpretação feita pelos partidos políticos do conteúdo das normas - que retém-se, comumente, apenas à aplicação do mínimo estabelecido -; além do já citado ínfımo reconhecimento de obrigatoriedade (ARCHENTI; ALBAINE, 2018).

Marque-se, ainda, que os partidos políticos são uma peça-chave para entender a não vinculação automática das cotas a resultados mais expressivos do que os vigentes. Na análise de Moisés e Sanchez (2014), frisa-se que a regra imposta pela legislação não impede que, em seu funcionamento, os partidos realizem processos informais de escolhas e concentrem as candidaturas sobre determinados candidatos, em consonância com interesses especialmente econômicos.

Com efeito, mesmo com as ações efetuadas pelas legislações mencionadas e com todo avanço social e jurídico no combate à discriminação contra as mulheres, o principal mecanismo da adoção da perspectiva de gênero na democracia representativa brasileira- as cotas de gênero - ainda é insuficiente para moldar um cenário de maior representação política feminina.

Entretanto isso não desconfigura a sua importância. Somando-se à pequena, mas existente, evolução numérica nas candidaturas femininas com a formulação e as reformulações da legislação de cotas, Archenti e Albaine (2018) citam como efeitos positivos de sua adoção: a ampliação da democratização dos parlamentos; o reconhecimento, em nível institucional, das diferenças de gênero na política e; as possibilidades de maior aproximação da agenda legislativa dos interesses das mulheres da sociedade civil, por meio das que passaram a assumir cargos políticos após a implementação das cotas.

Como hipótese de ação, indica-se que a evolução das cotas para a paridade política em nível normativo, como anunciado por Archenti e Albaine (2018) e Martelotte (2016), poderia ajudar a equilibrar a cena política, uma vez que se ultrapassaria a ideia de uma garantia mínima de vagas em candidaturas, para se falar em listas, ao menos formalmente, igualitárias quanto ao gênero.

Parlamentares mulheres já postulam também pela reserva de assentos nas Casas Legislativas, a fim de garantir que a população feminina venha, concretamente, a ocupar as instâncias de deliberação política com capacidade para influenciar nas decisões nelas tomadas. Projeto dessa espécie já chegou a ser veiculado pela Proposta de Emenda Constitucional (PEC) 23/2015, de autoria da senadora Vanessa Grazziotin, que pleiteava pela paridade nas cadeiras - e não nas listas de candidaturas - da Câmara dos Deputados e Assembleias Legislativas. A proposta, no entanto, regrediu para uma reserva de, respectivamente, $10 \%, 12 \%$ e $15 \%$ nas legislaturas seguintes, mas, mesmo com o recuo, não obteve êxito em ser aprovada (SANTOS, 2015).

Porém, não se tangencia da discussão que qualquer instrumento normativo que vise promover a igualdade de gênero na política, seja ele paritário ou afirmativo, não possa caminhar sozinho, nem tam- 
pouco desconsiderar o contexto específico de desigualdade de gênero do Estado que o adota. Políticas de cotas convivem com aspectos que vão além de mudanças institucionais, de modo que sua efetividade se condiciona também a alterações sociais estruturais no ideário de desigualdades dominante na sociedade, na família e nos partidos políticos (PRÁ, 2014).

Por outro lado, é indispensável que qualquer agenda de direitos das mulheres não feche os olhos às condições de educação, renda e trabalho que são distribuídas em proporções distintas para homens e mulheres na sociedade brasileira e que são mediadas por discriminações como as de gênero e de raça (BIROLI, 2018). Assim sendo, reafirma-se a posição de Pinto (2017), quando analisa o feminino dentro da ótica do reconhecimento e da redistribuição: não há igualdade de gênero na política sem igualdade socioeconômica e cultural entre homens e mulheres.

Reconhecidos a importância da adesão pelo Brasil às cotas de gênero e os tímidos avanços provenientes dela, nota-se que não há uma única fórmula que indique com precisão uma solução para sua maior eficácia nas candidaturas femininas e nos resultados eleitorais, pois esta perpassa por fatores multidimensionais e de ocorrência concomitante.

\section{CONSIDERAÇÕES FINAIS}

Esmiuçando formulações iniciais sobre o entrelaçamento entre gênero, democracia e representação política, pôde-se constatar, primeiramente, que o gênero é uma dimensão indispensável para a compressão do fenômeno estudado, porquanto suas hierarquias persistem sedimentando assimetrias no acesso e estabelecimento de carreiras na vida política e não se exteriorizam de modo neutro, interagindo com aspectos como a raça e a classe social.

Em uma abordagem posterior, concentrou-se no discurso teórico acerca das políticas de reconhecimento e na compreensão de que elas se encontram, não raras vezes, em situação de dependência para com as políticas redistributivas. Posicionou-se determinados grupos, como é o caso das mulheres, como segmentos sociais que sofrem simultaneamente de injustiças culturais e socioeconômicas. Na representação política, as abordagens estudadas tematizaram na perspectiva do reconhecimento a exigência de pluralizar o debate público através das percepções distintas dos diversos atores sociais e, no que toca ao gênero, as cotas eleitorais se colocam como mecanismos especiais temporários para esses fins.

Dentro desse viés, o Brasil implementou as cotas eleitorais de candidaturas no final da década de 1990, para cargos ocupados através do sistema proporcional. No entanto, a primeira das principais constatações feita foi que as cotas trouxeram à tona o debate sobre a visão social excludente entre a mulher e a política, mas não representaram um automático avanço expressivo das candidaturas femininas. Embora os índices de representação feminina tenham aumentado, continuam em proporção muito inferior aos masculinos.

Por trás disso, se levantou duas espécies de fatores que influem na capacidade de ação das cotas: os institucionais e os socioeconômicos/culturais. Os primeiros apontaram para aspectos como o comportamento excludente de muitos partidos políticos e o próprio texto legal, que não impõe penalidade para o descumprimento da reserva. Os segundos indicaram que as desigualdades socioeconômicas são determinantes no acesso feminino à política e que mudanças culturais profundas na estrutura social, no sentido de afastar a visão social de exclusão das mulheres da arena pública, são necessárias.

Em arremate, como constatação final, confirma-se que as cotas tiveram relativo êxito na intenção de promover a igualdade de gênero e isso ocorreu porque, se por um lado, elevou-se a visibilidade sobre 
os direitos políticos das mulheres, por outro, as cotas dependem de uma convicção de obrigatoriedade para surtirem efeitos mais concretos, como também da evolução das condições socioeconômicas das mulheres brasileiras e da superação de discriminações, tanto de gênero, como de raça e de classe.

\section{REFERÊNCIAS}

ARCHETI, Nélida; ALBAINE, Laura. O Feminismo na política. Paridade e violência política de gênero na América Latina. In: Cadernos Adenauer XIX (2018), n 1, Participação política feminina na América Latina. Rio de Janeiro: Fundação Konrad Adenauer, 2018. p. 9-24.

BIROLI. Flávia. Gênero e desigualdades: limites da democracia no Brasil. São Paulo: Boitempo, 2018.

BRASIL. Decreto ${ }^{\circ}$ 4.377, de 13 de setembro de 2002. Promulga a Convenção sobre a Eliminação de Todas as Formas de Discriminação contra a Mulher, de 1979, e revoga o Decreto no 89.460, de 20 de março de 1984. Brasília, DF: Presidência da República, [2002]. Disponível em: http://www.planalto.gov. br/ccivil_03/decreto/2002/D4377.htm. Acesso em: 09 nov. 2019.

BRASIL. Lei no 12.034, de 29 de setembro de 2009. Altera as Leis nos 9.096, de 19 de setembro de 1995 - Lei dos Partidos Políticos, 9.504, de 30 de setembro de 1997, que estabelece normas para as eleições, e 4.737, de 15 de julho de 1965 - Código Eleitoral. Brasília, DF: Presidência da República, [2009]. Disponível em: http://www.planalto.gov.br/ccivil_03/_Ato2007-2010/2009/Lei/L12034.htm. Acesso em 26 nov. 2019.

BRASIL. Tribunal Superior Eleitoral. Estatísticas eleitorais. 2019. Disponível em: http://www.tse.jus.br/ eleicoes/estatisticas/estatisticas-eleitorais. Acesso em: 15 mar. 2020.

SHAW, Kimberlé. Documento para o encontro de especialistas em aspectos da discriminação racial relativos ao gênero. Rev. Estud. Fem., Florianópolis, v. 10, n. 1, p. 171-188, 2002. Disponível em:http:// www.scielo.br/scielo.php?script=sci_arttext\&pid=S0104-026X2002000100011\&lng=en\&nrm=iso. Acesso em: 20 ago. 2019.

FRASER, Nancy. Da redistribuição ao reconhecimento? Dilemas da justiça numa era "pós-socialista". Tradução: Julio Assis Simões. Cadernos de Campo (São Paulo, 1991), São Paulo, v. 15, n. 14-15, p. 231-239, 2006. Disponível em: https://www.revistas.usp.br/cadernosdecampo/article/download/50109/54229/. Acesso em: 10 mai. 2019.

MARTELOTTE, Lúcia. 25 anos de Aplicação de Leis de Cotas na América Latina: Um balanço da participação política das mulheres. Sur- Revista Internacional de Direitos Humanos, São Paulo, v.13, n. 24, p. 91-98, dez. 2016. Disponível em: https://bdjur.stj.jus.br/jspui/bitstream/2011/108501/25_anos_aplicacao_martelotte. pdf. Acesso em: 20 out. 2019.

MOISÉS, José Álvaro; SANCHEZ, Beatriz. Representação política das mulheres e Qualidade da Democracia: o caso do Brasil. In: 0 Congresso Nacional, os partidos políticos e o sistema de integridade: representação, participação e controle interinstitucional no Brasil contemporâneo. Rio de Janeiro: Fundação Konrad Adenauer, 2014. p. 89- 115.

PEQUIM. Declaração e Plataforma de Ação da IV Conferência Mundial Sobre a Mulher. Pequim, 1995. Disponível em: http://www.onumulheres.org.br/wp-content/uploads/2014/02/declaracao_pequim.pdf. Acesso em: 08 jan. 2020. 
PINTO, Céli Regina Jardim. Feminismo, história e poder. Rev. Sociol. Polit., Curitiba, v. 18, n. 36, p. 15-23, jun. 2010. Disponível em: http://www.scielo.br/scielo.php?script=sci_arttext\&pid=S0104$44782010000200003 \&$ Ing=en\&nrm=iso. Acesso em: 25 out. 2019.

PINTO, Céli Regina Jardim. Redistribuir e reconhecer: aportes para a igualdade. In: MIGUEL, Luis Felipe; BIROLI, Flávia (org.). Encruzilhadas da democracia. Porto Alegre: Zouk, 2017, p. 147-167.

PRÁ, Jussara Reis. Mulheres, direitos políticos, gênero e feminismo. Cadernos Pagu, [s.I], n. 43, p. 169-196, dez. 2014. Disponível em: https://periodicos.sbu.unicamp.br/ojs/index.php/cadpagu/article/ view/8645135. Acesso em 20 fev. 2020.

RIBEIRO, Djamila. 0 que é lugar de fala? Belo Horizonte: Letramento, 2017.

SABINO, Maria Jordana Costa; LIMA, Patrícia Verônica Pinheiro Sales. Igualdade de gênero no exercício do poder. Revista Estudos Feministas, Florianópolis, v. 23, n. 3, p.713-734, dez. 2015. Fap UNIFESP (SciELO). Disponível em: http://www.scielo.br/scielo.php?script=sci_arttext\&pid=S0104-026X2015000 300713\&lng=pt\&tlng=pt>. Acesso em: 14 out. 2019.

SANTOS, Boaventura de Sousa; NUNES, João Arriscado. Introdução: para ampliar o cânone do reconhecimento, da diferença e da igualdade. In: SANTOS, Boaventura de Sousa. Reconhecer para libertar: os caminhos do cosmopolitismo multicultural. Rio de Janeiro: Civilização Brasileira, v. 3, 2003, p. 25-68.

SANTOS. Jahyra Helena Pequeno dos. Participação política feminina: a busca pela igualdade de gênero. 2015. 129 f. Dissertação (Mestrado) - Universidade de Fortaleza, Fortaleza, 2015, 129 f.

SCOTT, Joan. Gênero: uma categoria útil para análise histórica. Tradução: Christiane Rufıno Dabat e Maria Betânia Ávila, [s.I], 1990. Disponível em: http://moodle.stoa.usp.br/mod/resource/view.php?id=39565. Acesso em: 06 jan. 2019.

YOUNG, Iris Marion. Representação política, identidade e minorias. Tradução: Alexandre Morales. Lua Nova, São Paulo, n. 67, 2006. Disponível em: http://www.scielo.br/pdf/ln/n67/a06n67.pdf/. Acesso em: 05 jan. 2019. 